\title{
Pregnant mice submitted to Surgical Embryo Euthanasia (SEE) induce loss of expression of inducible nitric oxide synthase isoform and NO concentration in the maternal-fetal interface
}

\section{Lidia Jacinta Nunes Fernandes and Eliana Mara Oliveira Lippe*}

Department of Histology. University of Nine of July (UNINOVE). Bauru-SP, Brazil (CEP 17011-102).*Email: elianalippe@yahoo.com.br.

\begin{abstract}
The well-succeeded pregnancy in humans and rodents is the consequence of close interaction between maternal and fetal cells with intervening of cytokines and chemical mediators. In this process a pregnant uterus subset NK cells - uterine Natural Killer cells (uNK cells) play a pivotal modulatory role under the influence of local physiological hypoxia and other alterations. The aim of the present work was to evaluate the expression and commitment of induced form of nitric oxide synthase (iNOS) and NO concentration in the homeostasis of pregnant uterus. It was used normal pregnant mice on gd 10th and those submitted to surgical intervention to induce mechanical lesion in the embryos (SEE). Uterine samples were collected at $0.5,1,2$ and $6 \mathrm{~h}$ after embryo lesion and processed for paraffin embedding and tissue homogenate. The samples destinate for paraffin embedding was performed the Dolichos biflorus (DBA) lectin cytochemistry and anti-iNOS immunocytochemistry. The samples destinate to tissue homogenates were processed for SDS-PAGE and Western-blot using anti-iNOS and evaluate of NO concentration. The embryoinjured uterine segments showed hyperemia and hemorrhage at mesometrial region in which the DBA lectin reaction showed altered uNK cells suggesting the degranulation. Positive reaction with anti-iNOS was seen on uNK cells, trophoblast giant cells, endometrial stromal and decidual cells and smooth muscle cells in the normal pregnant uterus, but 1 and $2 \mathrm{~h}$ after embryo lesion, the iNOS labeling decreased or was absent only in uNK cells. The same results was obtained with NO concentration. These results confirm the unique constitutive expression of iNOS in the pregnant mice uterus, being the uNK cells the only one responsive against stress of embryo failure, besides showing that excessive NO produced by quick activation of uNK-iNOS should affect the local vascular permeability.
\end{abstract}

Received

February 5, 2020

Accepted

March 18, 2020

Available on line on

April 7, 2020

Released

April 30, 2020

Full Text Article

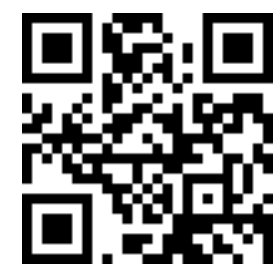

ORCID

(D) 0000-0002-4704-9368 Lidia Jacinta Nunes Fernandes

(1) 0000-0003-4802-8830 Eliana Mara Oliveira Lippe 
Keywords: Natural killer cells; Nitric oxide; Nitric oxide synthase; Pregnancy mouse; iNOS and NO in the uterine maternal-fetal interface.

\section{Introduction}

The successful embryo implantation and development in human and rodents uterus is highly dependent of interaction and dialogue between maternal and fetal cells, with intervention of the cytokines and chemical compounds in fine balance (Dietl et al., 2006; Sojka et al., 2019). This dialogue involves the blood vessels, stromal cells and leukocytes in the endometrium from maternal side, and trophoblast cells from the embryo in a complex signaling network (Burton et al., 2009). Unbalance of these signals could result miscarriage (Dietl et al., 2006; Sojka et al., 2019). Intriguing was the participation of uterine natural killer cells ( $\mathrm{uNK}$ ) - a lymphocyte population that accumulates in the uterine environment specifically during pregnancy (Saito et al., 2000; Lima et al., 2014). In human, the CD56 bright/CD16 ${ }^{\mathrm{dim}}$ uNK cells can be distinguished from the CD56 dim/CD16 ${ }^{\text {bright }}$ blood circulating NK (cNK) cells; the comparative microarray analyses showed several qualitative and quantitative differences on gene expression profile between these two NK cell subsets (Peng et al., 2010). In mice, the only way to distinguish uNK from cNK is the expression of Gal-N-Ac containing glycoconjugates on the surface of uNK reactive to Dolichos biflorus (DBA) lectin (Paffaro-Jr et al., 2003). These subpopulations differ functionally both in human and murine pregnant uterus. The cNK subset is more cytotoxic, has many cytolytic granules and express members of killer immunoglobulin-like receptor (KIR) family (Maynard et al., 2008; Leonard et al., 2013) while, the uNK cells in spite of high granule contents has low cytotoxicity, does not express KIRs, and experimentally it is mainly cytokine producing subset (Koopman et al., 2003).

Several unexplained recurrent pregnant loss in humans beings suggests immune based-etiology and proposed the participation of uNK cells (Croy et al., 2010; Cheng et al., 2012), but they have not experimentally proved yet. Therefore, to fully understand the involvement of uNK cells in the pregnancy, it is necessary to study these cells both in normal and abnormal situation of pregnancy. Using transgenic, knockout and mutant mice raised important contribution to understand the pathophysiological roles of uNK in pregnancy (Raulet et al., 2006); however most of them have systemic effects affecting a given pathway not specific to uNK cells in the pregnant uterus.

Recently, we developed an experimental model of surgical lesion performed in the embryo of pregnant mice to induce abnormal pregnancy status in the uterine environment (Lima et al., 2012). In this animal, the uNK cells seem to release their granules contents and induced hyperemia as soon as 30min after lesion that increased to focal hemorrhage after 1-2 $\mathrm{h}$ localized in the mesometrial region. This is the region where uNK cells migrate and accumulate in the pregnant mice uterus. These hyperemia and hemorrhage were also seen in the non-manipulated embryo implantation sites of same animal, suggesting a systemic effect of some soluble factor rather than driven by cytolytic mediators like perforin, since the uNK did not seem to reach any target cell. Based on this evidence, it is plausible to suppose the involvement of nitric oxide (NO) - a potent vasoactive free radical which affects the vascular permeability (Gagioti et al., 2000; Murphy et al., 2005) and is an extremely unstable lipid-soluble gas and undergoes rapid oxidative degradation to the stable breakdown products nitrate and nitrite - and the inducible nitric oxide synthase (iNOS), the most effective catalytic enzyme to produce it; fact already described in mouse uNK cells (Hunt et al., 1997). Therefore, embryo failure could be closely related to changes on NO produced in the uterine environment, which affects the local homeostasis. 
In the present work, there were adopted the surgical embryonic damage in pregnant mice to evaluate comparatively the iNOS expression in the maternal-fetal interface of abnormal and normal pregnant mouse uterine environment. And we quantified the presence of NO byproducts, nitrate and nitrite, because the NO is a short-life radical and this is used as markers for the release of NO.

\section{Materials and methods}

\section{Animals}

Female and male Swiss mice aging 10-12 weeks old were purchased from Animal Facilities (CEMIB) of University of Campinas and housed under $12 \mathrm{~h}$ light/12 h dark to mate with free access to water and food. The 1st gestational day (gd) was considered to be the first morning presenting the vaginal plug. All the animal handling agreed with Brazilian College of Animal Experimentation and was approved by Animal Bioethics and Experimentation of Institute of Biology, University of Campinas, Brazil (Proc. No. 1144-2).

\section{Surgical Euthanasia of Embryo (SEE)}

Pregnant mice on gd 10 were anesthetized with intraperitoneal injection of $5 \mathrm{mg} / \mathrm{kg}$ of xylazine chloride (Anasedan, Brazil) and $100 \mathrm{mg} / \mathrm{kg}$ of ketamine (Sespo, Brazil). After laparatomy, the uterine horns were exposed and a $15 \times 5$ gauge needle was introduced into the uterine wall through the antimesometrial side to damage the developing embryo. At least, two interspersed embryos were lesioned on the left uterine horn, while the right uterine horn was not manipulated. The muscle and skin incisions were sutured and after recovering from the anesthesia the animals were hold in individual cage. The control animals were handled in the same way, except for the mechanical embryo lesion, and sacrificed after $0.5,1,2$ and $6 \mathrm{~h}$ of surgical procedure.

\section{Cytochemistry and immunocytochemistry}

At least, 3 animals from each experimental group of embryo lesioned or corresponding control animals were perfusion fixed with $30 \mathrm{~mL}$ of $4 \%$ paraformaldehyde (PFA) in $100 \mathrm{mM}$ PBS pH 7.4 through the left ventricle. The uterine fragments containing embryo development sites were processed according to the conventional paraffin embedding and $5 \mu \mathrm{m}$ thick paraffin sections were collected on silanized glass slides.

Dolichos biflorus (DBA) lectin cytochemistry was performed according to Paffaro Jr, et al. (2003). Briefly, desparaffinized sections were blocked with $1 \%$ bovine serum albumin (BSA type V, Sigma Chem. Co., St Louis, USA) in $100 \mathrm{mM}$ PBS pH 7.4 and incubated with biotinylated DBA lectin (Sigma Chem. Co., St Louis, USA). After treatment with streptavidin-peroxidase (Chemicon, USA), the peroxidase was revealed with $0.5 \%$ diaminobenzidine $(D A B)$ and hydrogen peroxide $\left(\mathrm{H}_{2} \mathrm{O}_{2}\right)$.

There were employed, on paraffin sections, immunoperoxidase using the mouse monoclonal anti-iNOS diluted in the $0.5 \mu \mathrm{g} / \mu \mathrm{L}$ concentration (1:200) (Sigma Chem. Co., Louis, USA) as primary antibody and peroxidase conjugated rabbit anti-mouse (Santa Cruz, USA) as secondary antibody. After revelation with DAB and $\mathrm{H}_{2} \mathrm{O}_{2}$, the sections were counterstained with hematoxylin and mounted with synthetic Canada balsam under coverslips.

\section{SDS-PAGE and Western-blot}

The mesometrial lymphoid aggregate of pregnancy (MLAp) region was dissected from 2 embryo lesioned sites of 3 different animals of each experimental group. These tissue samples in ice cooled bath were homogenized in $10 \mathrm{mM}$ Trizma base (Sigma Chem. Co., St Louis, USA) pH 7.4 containing 10 mM EDTA (Sigma Chem. Co., St Louis, USA), 10 mM sodium pyrophosphate (Sigma Chem. Co., St Louis, USA), $100 \mathrm{mM}$ sodium fluoride (Sigma 
Chem. Co., St Louis, USA), $10 \mathrm{mM}$ sodium orthovanadate (Sigma Chem. Co., St Louis, USA), $2 \mathrm{mM}$ PMSF (Sigma Chem. Co., St Louis, USA), $0.1 \mathrm{mg} / \mathrm{mL}$ aprotinin (Sigma Chem. Co., St Louis, USA) and 1\% igepal (Sigma Chem. Co., St Louis, USA) using Glass-Col (USA) homogenizer. The homogenates were centrifuged $(12,000 \mathrm{~g})$ for $30 \mathrm{~min}$ at $4{ }^{\circ} \mathrm{C}$ and the protein contents in the supernatants were evaluated according to Bradford et al. (1976).

The SDS-polyacrylamide gel electrophoresis were performed with $30 \mu \mathrm{g}$ proteins from each samples and Prestained SDS-PAGE Standards High Range (Bio Rad) as molecular weight marker in 7.5 slab gels $(8.5 \times 7.3 \mathrm{~cm})$ prepared according to Laemmli et al. (1970) using Mini Protean III system and Power Pac 300 (Bio Rad, USA) as power source. After eletrophoresis, the proteins were blotted to the membrane (ImmobilonP-Transfer Membrane, Millipore, USA). The membranes were washed in $100 \mathrm{mM}$ Tris-buffer $50 \mathrm{mM}$ with $0.5 \%$ Tween 20 (TBS-T) followed by blocking with 5\% defatted milk (Molico, Nestle, Brazil) in TBS-T and incubation with mouse monoclonal anti-iNOS (1:1000) overnight at $4{ }^{\circ} \mathrm{C}$. There were used peroxidase-conjugated rabbit anti-mouse polyclonal antibody for anti-iNOS and Luminol Kit (SuperSignal WestPicoChemiluminescent Substrate, Pierce, USA); the membranes were scanned for densitometry. The luminescence were quantified as pixels density using UN-SCAN-IT-5.1 (Silk Scientific Corp., Orem, UT) and the statistical significance $(\mathrm{P}<0.05)$ were evaluated with ANOVA.

\section{Nitrate and nitrite assay (NO)}

The sample of MLAp region were collected was performed according to the item 2.5 and was additionally centrifuged with centricon (Amicon, Inc, USA) during $30 \mathrm{~min}$, $12,000 \mathrm{~g}$ at $4{ }^{\circ} \mathrm{C}$ and storage to $-70{ }^{\circ} \mathrm{C}$ until the moment of use. The sample was diluted 1:10 in $100 \mathrm{mM} \mathrm{PBS} \mathrm{pH} \mathrm{7.4} \mathrm{to} \mathrm{determine} \mathrm{the} \mathrm{amount} \mathrm{of} \mathrm{nitrate} \mathrm{and} \mathrm{nitrite} \mathrm{by} \mathrm{colorimetric}$ test (Cayman Chemical, USA) and the reading was made in reader of ELISA (Molecular Devices, California 94089) and the analyses was made in program SoftmaxPro between 540 and $550 \mathrm{~nm}$. The sample was compared with standard curve of nitrate and nitrite. The statistics analyses of averages $\pm \mathrm{SD}$ and the degree of significance were made by ANOVA test.

\section{Results}

The uterus submitted to surgical euthanized of the embryos have shown hyperemia on the mesometrial side under macroscopic evaluation 1, 2 and $6 \mathrm{~h}$ after lesion and showed increase to localized hemorrhage. Those embryo developing sites surrounded the lesioned ones have shown the same hyperemic or hemorrhage reaction and the nonmanipulated right horn also showed the hyperemic reaction.

In the mesometrial half of each embryo developing sites in the normal pregnant uteri of gd 10 were distributed the DBA lectin positive uNK cells, with dominance of subtypes III and IV in the decidualized endometrium nearest the embryo and the subtypes I and II in the non-decidualized endometrium and myometrium. The uNK cells - in the uteri submitted to embryo damage changed the reaction pattern with DBA lectin; being noticeable the formation of large cytoplasmic vacuoles and loss of granules contents reactivity in the uNK subtypes III and IV since $1 \mathrm{~h}$ after lesion. After $6 \mathrm{~h}$, the uNK subtypes II also showed loss of reactivity in the granules.

The anti-iNOS immunocytochemistry performed in the normal pregnant uterus showed strong reaction in the cytoplasm of uNK cells (Figure 1a) and trophoblast giant cells (Figure 1b), and weak reaction in endometrial stromal cells and smooth muscle cells of myometrium (Figure 1c). In the embryo-lesioned samples, the reaction intensity did not change in trophoblast cells or in the endometrial stromal or myometrial cells. In the uNK cells, the reactions became weaker after 1 and $2 \mathrm{~h}$ (Figure 1d), if compared to those of 
normal pregnancy; and after $6 \mathrm{~h}$, the reactivity was restored in the most of uNK cells (Figure 1e).

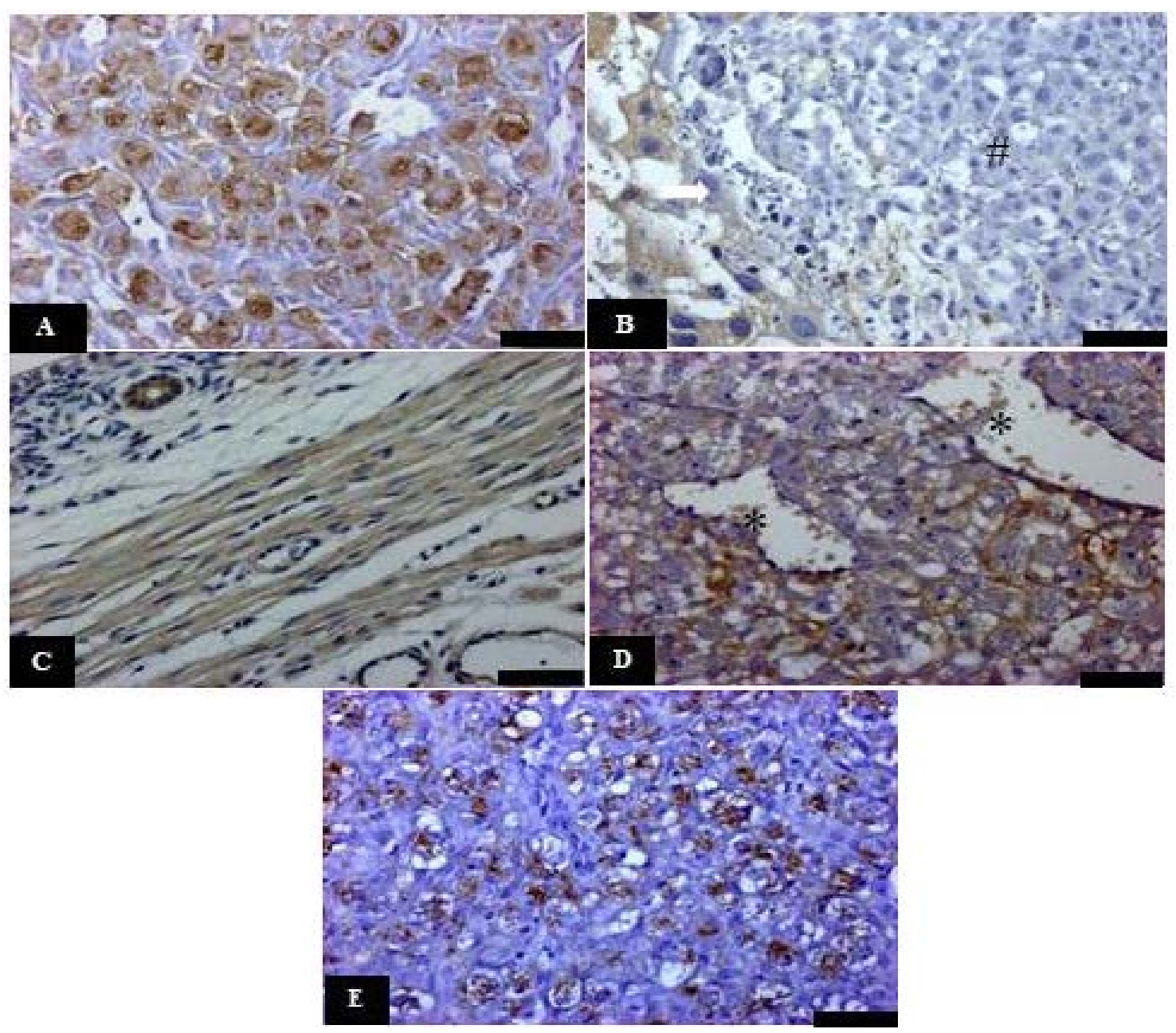

Figure 1. Photomicrographs of anti-iNOS immunoperoxidase reaction in pregnant mouse uterus on 10 th dg, counterstained with hematoxylin. A and B)- anti-iNOS positive reaction in the cytoplasm of uNK cells (arrows) and trophoblast giant cells (white arrows) in the uterus of normal pregnancy, respectively. ( ${ }^{*}$ ) blood vessels, (\#) antimesometrial decidual cells; C)- anti-iNOS positive reactions in the smooth muscle cells (arrows) of myometrium; D)- weak or absence of anti-iNOS reaction on most of uNK cells (arrows) after $2 \mathrm{~h}$ of embryo lesion. Note the blood cells retained in the enlarged blood vessels $\left(^{*}\right)$ even after vascular perfusion with fixative solution; E)- uNK cells showing antiiNOS positive reaction partially recovered beside other negatives (arrows) after $6 \mathrm{~h}$ of embryo lesion; Bars $=30 \mu \mathrm{m}$.

The same data was confirmed by Western blot and revealed a $130 \mathrm{kDa}$ single band reactive to anti-iNOS in all samples evaluated (Figure 2a). The densitometry analysis of the bands showed significant $(\mathrm{p}<0.05)$ decreased in the intensity at 1 and $2 \mathrm{~h}$ after embryo lesion compared to normal pregnancy and restoring on the intensity after $6 \mathrm{~h}$. The quantified of nitrate and nitrite showed a high proportion of free radicals in the form of nitrate and a low production in the form of nitrite and was observed peak of production after $0.5 \mathrm{~h}$ of SEE, reduce of production in $2 \mathrm{~h}$ and return of production in $6 \mathrm{~h}$ (Figure $2 \mathrm{~b}$ ). 


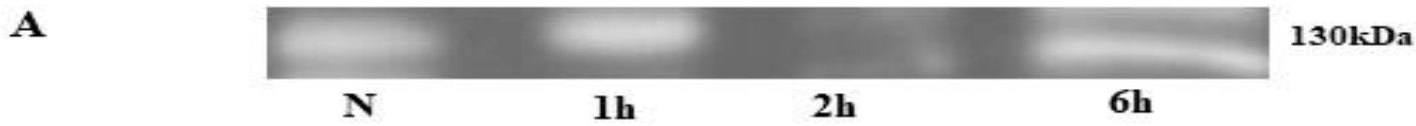

B

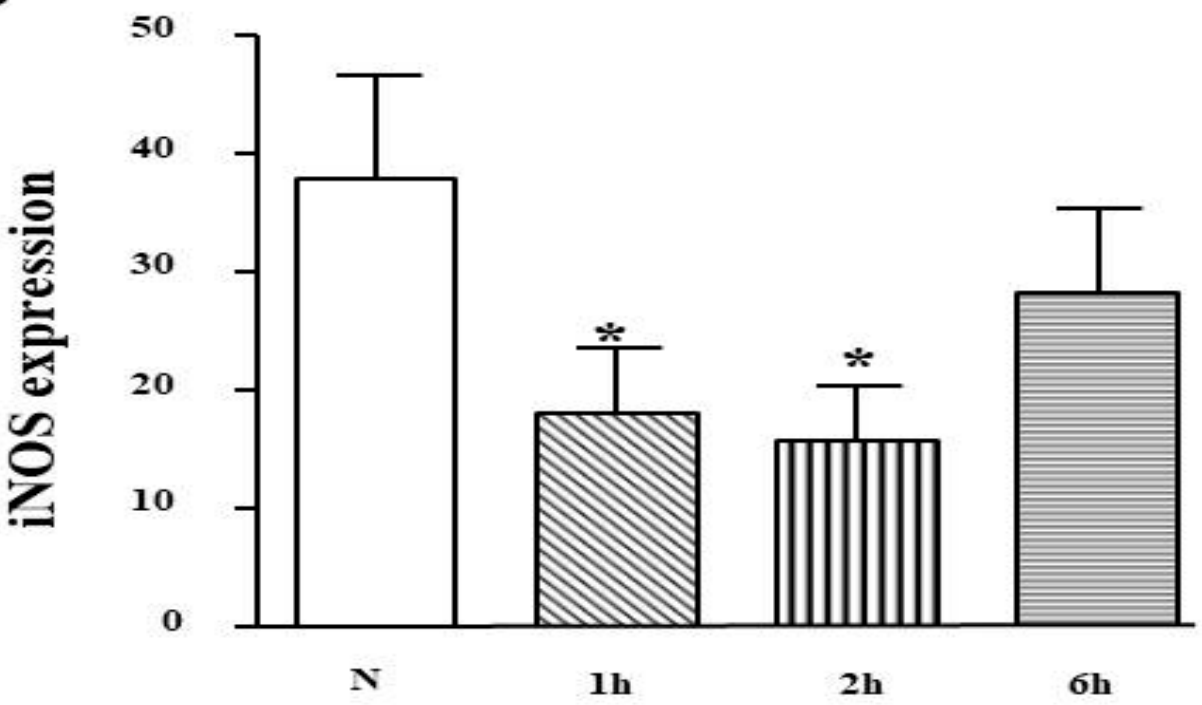

Figure 2. A)- Western-blot of iNOS revealed by chemoluminescence after SDS-PAGE of uterine homogenates from normal pregnancy (N), 1, 2, $6 \mathrm{~h}$ after embryo lesion and $6 \mathrm{~h}$ after LPS treatment. B)- histogram of the corresponding densitometry values showed significant low values $(p<0,05)$ at 1 and $2 \mathrm{~h}$ after lesion when compared to normal pregnant uterus.

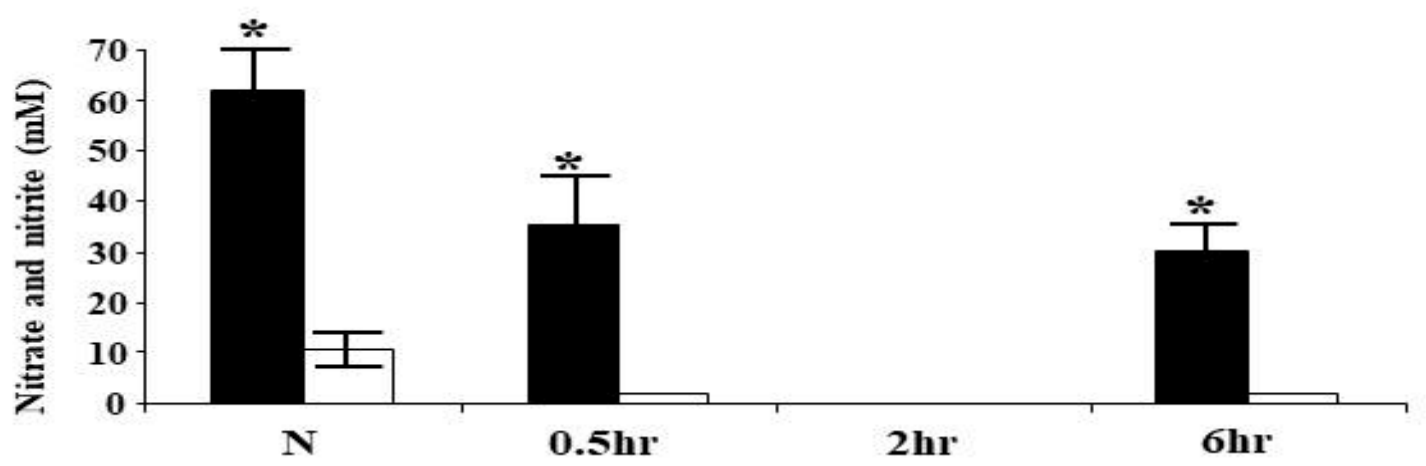

Figure 3. Nitrate and nitrite concentration in the uterus after SEE.

The quantification of nitrate and nitrite showed decreased in the production of NO after $0.5 \mathrm{~h}$ and completely loss in $2 \mathrm{~h}$ after SEE (Figure 3 ).

\section{Discussion}

The mechanism concerning the complex dialogue established between the cells of maternal-fetal interface in the pregnant uterus is still not completely understood, therefore, the need of assurance regarding the clinical intervention in the abnormal pregnancy or recurrent abortions. Development of experimental model of abnormal 
pregnancy to study changes in the maternal-fetal interface should be helpful to understanding the fine mechanism controlling the homeostasis of pregnant uterus.

Previously, we used the surgical intervention to induce embryo damage in pregnant mice and reported the changes on morphology and function of uNK cells committed to cytotoxic activity - in response to abnormal status of uterine environment (Lima et al., 2017). Also, was identified that SEE activated the regulated secretory pathway of DBA(+) uNK cells in vivo, mobilizing perforin and granzymes, but not Vegfa (Lima et al., 2014). The hyperemia and hemorrhage seen in the mesometrial side of the uterus were supposed to be the consequences of the embryo lesion involving the uNK cells.

Actually, the embryo lesion performed in the pregnant mice on gd 10 used in the present work showed a localized hyperemic reaction, as soon as $1 \mathrm{~h}$ after lesion, which evolved to hemorrhage after $2 \mathrm{~h}$, confirming the alteration on vascular permeability and/or disruption of vascular wall in the blood vessels of mesometrial side of the uterus. No noticeable damage on artery walls was observed under histological evaluation, suggesting the integrities of small venous type and capillaries vessels were mainly affected.

The DBA lectin cytochemistry is the most selective method to identify the uNK cells (Bulmer et al., 2019) in the pregnant mouse uterus. All the embryo-lesioned uteri samples showed changes in the pattern of DBA lectin reactivity of uNK cells with looseness of labeling in the granules contents, as was previously reported (Lima et al., 2017). The granules of uNK cells contain cytolitic proteins like perforin and granzymes (Baltayeva et al., 2019) and their degranulation and release of these mediators suggests activation of innate immune response. This is a unique pathophysiological response of uNK cells since it has longer been considered a non-killing NK cell in pregnant uterus (Raulet et al., 2006).

The expression of induced isoform of nitric oxide synthase (iNOS) in the pregnant uterus was already reported (Bulmer et al., 2019), beside our immunocytochemical, which data show its expression in trophoblast giant cell, endometrial stromal cells, uNK cells and myometrium smooth muscles. It confirms the pregnant uterine environment normally induces the expression of this NOS isoform to produce nitric oxide (NO) in the maternalfetal interface. $\mathrm{NO}$ is a short-lived free radical and intercellular messenger that mediates a variety of biological functions, including vascular homeostasis as vasodilating agents by relaxing arterial and venous smooth muscles (Madamanchi et al., 2005). The dg 10 is the period of intensive endometrial remodeling with angiogenesis required for the organogenesis of the placenta in pregnant mouse uterus; and this process of neovascularization results from hypoxia and induction of various angiogenic factors - the basic conditions that are necessary to support embryo development in the endometrial of animals of hemochorial type placentation.

Among the cells in the uterus showing iNOS expression, the uNK cells should play a crucial role in the angiogenesis due to their localization at mesometrial side closely associated to the spiral arteries and interposing the maternal interface to the growing placenta. Therefore, hyperemia and hemorrhage in this area after embryo lesion seems to be consequence of imbalance of NO produced in high level by uNK cells. On the other hand, the oxidative stress, which is defined as toxicity inflicted by reactive oxygen species (ROS) and reactive nitrogen species (RNS), including NO is assumed to contribute to the state of immunosuppression by inhibiting the function of NK cells and other lymphocytes, being interesting that IL-2 and other NK-cell-activating cytokines are ineffective in an environment of oxidative stress (Baltayeva et al., 2019). Therefore, the NO produced by uNK cells could be an autocrine or intracrine-like action to down-regulate the cytotoxic activity of theses cells in the normal pregnant uterus.

It was intriguing the decreasing on reactivity of iNOS detected by immunolabeling only in uNK cells of the uteri after 1 and $2 \mathrm{~h}$ embryo lesion. It suggests different mechanisms modulating the iNOS expression and activation of the cells in maternal-fetal 
interface. The bypass of iNOS-NO production in up-regulated oxidative stress status of living tissues like in burn-trauma occurs in first hour after trauma (Horton et al., 2003). In the case of uNK cells, they synthesize iNOS "constitutively" under normal pregnancy and it is available for quick mobilization to catalyze the NO production.

According to Haddad et al (1995) the production of nitrate is more sensible than production of nitrite and this used to determine the amount total of NO present in the half after the diverse treatments.

However, it is reasonable to suppose the response of uNK cells under embryo trauma increasing the demand of local oxygenation to increase the production of NO by fast consumption of iNOS. This was detected as reduced or absence of immunolabeling in the 1 and $2 \mathrm{~h}$ after embryo lesion. The peak of iNOS production in resting cells is usually observed after $0.5 \mathrm{~h}$ of embryo lesion, but since the iNOS is "constitutively" produced by many cells in the pregnant uterus their NO production could be catalyzed faster than any other place. Therefore, the imbalanced high production of NO - by activating the iNOS enzyme available in the uNK cells, which are located at the mesometrial half of the embryo developing site - should be determinant of increased vascular permeability resulting in hyperemia and hemorrhage seen in this uterine region. In fact, the Western-blot analysis confirmed the lowering of iNOS expression at 1 and $2 \mathrm{~h}$ after embryo lesion if compared to normal animals, which should be the relative amount of iNOS disposed by uNK cells in the pregnant uterus and the remainder level belonging to the other iNOS positive cells, which are not affected by or responsive to embryo lesion.

In fact, the immunocytochemistry showed changes on iNOS only in the uNK cells. However, since in the uterus many cells, including the uNK, showed constitutive expression during pregnancy, it must be revised in the future by additional experiment focusing the uNK cells to evaluate them at shorter and longer time rather the conventional $6 \mathrm{~h}$ used in other organs and tissues.

It was the unequivocal involvement of uNK cells and iNOS in the abnormal status of pregnancy induced by two different models of embryo failure used in the present work and therefore, evaluations of the iNOS and NO levels could be helpful as additional parameter to early evaluation for clinical diagnosis in many cases of pregnancy failure.

\section{Acknowledgements}

We would like to thank Dr. Aureo Yamada from the University of Campinas (UNICAMP, Brazil) for the help with the manuscript preparation and Dr. B. Anne Croy (Queen's University, Kingston, Canada) for valuable and critical revision of this manuscript. Grant support: This study was supported by Federal Agency for Support and Evaluation of Graduate Education-CAPES, Brazil, grant No. 4683-08-0.

\section{Conflicts of interest}

The author declares that have no conflict of interests.

\section{References}

Baltayeva, J.; Konwar, C.; Castellana, B.; Mara, D. L.; Christians, J. K.; Beristain, A. G. Obesogenic diet exposure alters uterine natural killer cell biology and impairs vasculature remodeling in mice. Biology of Reproduction, v. 102, no. 1, p.63-75, 2019. https://doi.org/10.1093/biolre/ioz163 
Bradford, M. M. A rapid and sensinte method for quantification of microgram quantities of protein utilizing the principle of protein-dye binding. Analytical Biochemistry, v. 72, no. 1/2, p. 248-254, 1976. https://doi.org/10.1016/0003-2697(76)90527-3

Bulmer, J. N.; Lash, G. E. Uterine natural killer cells: Time for a re-appraisal? [version 1; peer review: 2 approved]. F1000Research, v. 8, 2019. https://doi.org/10.12688/ f1000research.19132.1

Burton G. J.; Charnock-Jones, D. S.; Jauniaux E. Regulation of vascular growth and function in the human placenta. Reproduction, v.138, p.895-902, 2009. https://doi.org/ 10.1530/REP-09-0092

Cheng, Z.; Zhang, J.; Hatta, K.; Lima, P. D.; Yadi, H.; Colucci, F.; Yamada, A. T.; Croy, B. A. DBA-lectin reactivity defines mouse uterine natural killer cells subsets with biased gene expression. Biology of Reproduction, v. 87, no. 4, p.81-87, 2012. https://doi.org/ 10.1095/biolreprod.112.102293

Chiokadze, M.; Kristesashivili, J. On the issue of standardization of uterine natural killer cell measurement in patients with recurrent pregnancy loss. Georgian Medical News, v. 294, p. 31-36, 2019.

Croy, B. A.; Ashkar, A. A.; Foster, R. A.; DiSanto, J. P.; Magram, J.; Carson, D.; Gendler, S. J.; Grusby, M. J.; Wagner, N.; Muller, W.; Guimond, M. J. Histological studies of gene-ablated mice support important functional roles for natural killer cells in the uterus during pregnancy. Journal of Reproductive Immunology, v. 35, no. 2, p. 111-133, 1997. https://doi.org/10.1016/s0165-0378(97)00054-5

Croy, B. A.; Zhang, J.; Tayade, C.; Colucci, F.; Yadi, H.; Yamada, A. T. Analysis of uterine natural killer cells in mice. In: Campbell, K. (Ed.). Natural killer cell protocols. New York: Humana Press, 2010. (Methods in Molecular Biology (Methods and Protocols), v. 612). p. 465-503. https://doi.org/10.1007/978-1-60761-362-6_31

Dielt, J.; Honig, A.; Kammerer, U.; Rieger, L. Natural killer cells and dendritic cells at the human feto-maternal interface: An effective cooperation. Placenta, v. 27, no. 4/5, p. 341347, 2006. https://doi.org/10.1016/j.placenta.2005.05.001

Haddad, E. K.; Duclos, A. J.; Baines, M. G. Early embryo loss is associated with local production of nitric oxide by decidual mononuclear cells. Journal of Experimental Medicine, v. 182, no. 4, p. 1143-1152, 1995. https://doi.org/10.1084/jem.182.4.1143

Horton, J. W. Free radicals and lipid peroxidation mediated injury in burn trauma: The role of antioxidant therapy. Toxicology, v. 189, no. 1/2, p.75-88, 2003. https://doi.org/ 10.1016/s0300-483x(03)00154-9

Hunt, J. S.; Miller, L.; Vassmer, D.; Croy, B. A. Expression of the inducible nitric oxide synthase gene in mouse uterine leukocytes and potential relationships with uterine function during pregnancy. Biology of Reproduction, v. 57, no. 4, p. 827-836, 1997. https://doi.org/10.1095/biolreprod57.4.827

Koopman, L. A.; Kopcow, H. D.; Rybalov, B.; Boyson, J. E.; Orange, J. S.; Schatz, F.; Masch, R.; Lockwood, C. J.; Schachter, A. D.; Park, P. J.; Strominger, J. L. Human decidual natural killer cells are a unique NK cell subset with immunomodulatory potential. Journal of Experimental Medicine, v. 198, no. 8, p.1201-1212, 2003. https://doi.org/ 10.1084/jem.20030305

Laemmli, U. K. Cleavage of structural proteins during the assembly of the head of bacteriophage T. Nature, v. 227, p. 680-685, 1970. https://doi.org/10.1038/227680a0 
Leonard, S.; Lima, P.D.; Croy, B. A.; Murrant, C. L. Gestational modification of murine spiral arteries does not reduce their drug-induced vasoconstrictive responses in vivo. Biology of Reproduction, v. 89, no. 6, 139, 2013. https://doi.org/10.1095/biolreprod.113.113688

Lima, P. D.; Croy, B. A.; Degaki, K. Y.; Tayade, C.; Yamada, A. T. Heterogeneity in composition of mouse uterine natural killer cell granules. Journal of Leukocyte Biology, v. 92, no. 1, p. 195-204, 2012. https://doi.org/10.1189/jlb.0312136

Lima, P. D.; Chen, Z.; Tayab, A.; Murphy, M. S.; Pudwell, J.; Smith, G. N.; Croy, B. A. Circulating progenitor and angiogenic cell frequencies are abnormally static over pregnancy in women with preconception diabetes: A pilot study. PLoS ONE, v. 12, no. 3, e0172988, 2017. https://doi.org/10.1371/journal.pone.0172988

Lima, P. D.; Zhang, J.; Dunk, C.; Lye, S. J.; Croy, B. A. Leukocyte driven-decidual angiogenesis in early pregnancy. Cellular \& Molecular Immunology, v. 11, no. 6, p. 522-537, 2014. https://doi.org/10.1038/cmi.2014.63

Madamanchi, N. R.; Vendrov, A.; Runge, M. S. Oxidative stress and vascular disease. Arteriosclerosis, Thrombosis, and Vascular Biology, v. 25, no. 1, p. 29-38, 2005. https://doi.org/10.1161/01.ATV.0000150649.39934.13

Maynard, S. E.; Moore Simas, T. A.; Solitro, M. J.; Rajan, A.; Crawford, S.; Soderland, P.; Meyer, B. A. Circulating angiogenic factors in singleton vs multiple-gestation pregnancies. American Journal of Obstetrics \& Gynecology, v. 198, no. 2, p. 200.e1-200.e7, 2008. https://doi.org/10.1016/j.ajog.2007.08.042

Murphy, S. P.; Fast, L. D.; Hanna, N. N.; Sharma, S. Uterine NK cells mediate inflammation-induced fetal demise in IL-10 null mice. The Journal of Immunology, v.175, no. 6, p. 4084-4090, 2005. https://doi.org/10.4049/jimmunol.175.6.4084

Paffaro, V. A. Jr.; Bizinotto, M. C.; Joazeiro, P. P.; Yamada, A. T. Subset classification of mouse uterine natural killer cells by DBA lectin reactivity. Placenta, v. 24, p. 479-488, 2003. https://doi.org/10.1053/plac.2002.0919

Peng, B.; Koga, K..; Cardenas, I.; Aldo, P.; Mor, G. Phagocytosis of apoptotic trophoblast cells by human endometrial endothelial cells proinflammatory cytokine production. American Journal of Reproductive Immunology, v. 64, no. 1, p. 12-19, 2010. https://doi.org/ 10.1111/j.1600-0897.2010.00815.x

Raulet, D. H.; Vance, R. E. Self-tolerance of natural killer cells. Nature Review Immunology, v. 6, no. 7, p. 520-531, 2006. https://doi.org/10.1038/nri1863

Saito S. Cytokine network at the feto-maternal interface. Journal of Reproductive Immunology, v. 47, no. 2, p.87-103, 2000. https://doi.org/10.1016/s01650378(00)00060-7

Sojka, D. K.; Yang, L.; Yokoyama, W. M. Uterine natural killer cells. Frontiers of Immunology, v. 10, 2019. https://doi.org/10.3389/fimmu.2019.00960

License information: This is an open-access article distributed under the terms of the Creative Commons Attribution License, which permits unrestricted use, distribution, and reproduction in any medium, provided the original work is properly cited. 